\title{
O QUE PODE UM CORPO EM TEMPOS DE CATÁSTROFE? PROCESSOS DE SUBJETIVAÇÃO NA CONTEMPORANEIDADE
}

\author{
WHAT IS A BODY ABLE TO DO IN TIMES OF CATASTROPHE? PROCESSES OF \\ SUBJECTIVITY IN CONTEMPORANEITY
}

\author{
Terezinha Maria Schuchter ${ }^{1}$ \\ Fábio Luiz Alves de Amorim² \\ Jaconias Dias Rodrigues ${ }^{3}$
}

\begin{abstract}
Resumo: Objetiva tecer problematizações sobre a conjuntura atual, discutindo processos de subjetivação na contemporaneidade, a partir de Rolnik, Lazzarato, Hardt e Negri, lançando apostas que transitam entre o resistir, o insurgir e o engendrar novos modos de ser e estar no mundo. Recorre a uma pesquisa bibliográfica, para discutir como chegamos a esse estado de coisas, desnaturalizando os fenômenos vividos, tomando-os como uma construção humana e intencional. Aponta que, apesar de vivermos um momento da mais alta periculosidade, que afeta não apenas questões da ordem econômica, mas dimensões ligadas ao nosso corpo, às nossas vidas, aos processos de subjetivação, não podemos sucumbir. Aposta na utilização de mecanismos disparadores de outras subjetividades que problematizem o que vem sendo produzido pelo regime atual, que questionem e duvidem das práticas discursivas que querem nos fazer acreditar que tudo o que vivemos hoje decorre de uma ordem natural e inevitável.
\end{abstract}

Palavras-chave: Corpos; subjetivação; neoliberalismo.

\begin{abstract}
It aims to question about the current situation, discussing processes of subjectivity in the contemporary world, from Rolnik, Lazzarato, Negri and Hardt, with ideas that pass through resisting, uprising and engendering new ways of existing and being inserted in the world. It uses a bibliographic research to analyze how we came to this state of affairs, denaturalizing the phenomena experienced, taking them as a human and intentional construction. It points out that, despite living in a moment of the highest dangerousness, which affects not only the economic order, but dimensions connected to our body, to our lives and to the processes of subjectivity, we cannot surrender. It counts on the use of mechanisms to trigger other subjectivities that question what has been produced by the current government, that question and doubt the discursive practices that want to make us believe that everything we live today results from a natural and inevitable order.
\end{abstract}

Keywords: Bodies; subjectivity; neoliberalism.

\section{Introdução}

Nossa intenção é problematizar a conjuntura política, econômica, social e cultural instaurada e os processos de subjetivação na contemporaneidade, a partir de Rolnik (2018, [201]), Lazzarato (2006, 2014, 2017), Hardt e Negri (2005, 2016a, 2016b), lançando apostas que transitam entre o resistir, o insurgir e o engendrar novos modos de ser e estar no mundo. Recorremos, assim, a uma pesquisa bibliográfica, no sentido de trazer elementos à compreensão de como chegamos a esse estado de coisas, desnaturalizando os fenômenos vividos e os tomando como uma construção histórica, humana, intencional. "Saber como chegamos a ser o

\footnotetext{
${ }^{1}$ Universidade Federal do Espírito Santo.E-mail: terezaschuchter@yahoo.com.br.

${ }^{2}$ Faculdade Estácio de Sá de Vitória. E-mail: fabioamorim36@gmail.com.

${ }^{3}$ Secretaria Municipal de Educação da Serra. E-mail: jaconiasdias@gmail.com.
} 
que somos é condição absolutamente necessária, ainda que insuficiente, para resistir, para desarmar, reverter, subverter o que somos e o que fazemos" (VEIGA-NETO, 2003, p. 7).

Esses autores têm se dedicado a discutir as subjetividades que têm sido produzidas no contexto atual - o endividado, o mediatizado, o securitizado, o representado, o angustiado - que exploraremos a seguir. São subjetividades que corroboram para a consolidação de uma política de inconsciente dominante, designada por Rolnik (2018) de inconsciente colonial-cafetinístico, pelo poder de sequestro da força vital, da potência do vivo. Negri (2015) também aponta que, no atual estágio do capitalismo financeirizado e neoliberal, o capital já considera sua regulação não mais na relação entre a fábrica e a sociedade, mas no nível social, das formas de exploração da vida, e isso, segundo o autor, já era problematizado na década de 1970 por alguns companheiros ${ }^{4}$ de trabalho, que mostravam que o capitalismo passava a exercer não só a função de controle da sociedade, mas que entrava no corpo da vida. "O mundo do trabalho explora enquanto bios", ou seja, não explora mais apenas a "força de trabalho e sim como forma viva, não só como máquina de produção e sim como corpo comum da sociedade" (NEGRI, 2015, p. 61).

Por que cafetinístico? Porque assim como a base da economia capitalista se constitui por meio da exploração da força de trabalho para extrair a mais valia, na sua nova versão, o capital se apropria da própria vida, da sua potência de criação e transformação em seu nascedouro, da sua essência germinativa, da cooperação da qual tal potência depende para que se efetue em sua singularidade. "A força vital de criação e cooperação é assim canalizada pelo regime para que construa um mundo segundo seus desígnios". Assim, a "fonte da qual o regime extrai sua força não é mais apenas econômica, mas também intrínseca e indissociavelmente cultural e subjetiva [...]". Isso lhe confere “[...] um poder mais amplo, mais sutil e mais difícil de combater." (ROLNIK, 2018, p. 32-33). Nós acrescentaríamos que esse poder se expande para o domínio e a colonização do corpo.

O controle, do corpo, da vida, da subjetividade, é um dos traços fundamentais do regime capitalista neoliberal. O intuito não é apenas deixar o corpo dócil, mas acelerar sua capacidade de produzir o que interessa ao regime, desviando-o de seu destino ético, que é a capacidade de criação associada à vida. Nessa armadilha, nossos corpos passam a reproduzir o status quo.

Antes eram os corpos dóceis, disciplinados, submissos; agora são necessários corpos flexíveis, voláteis, conectados, que circulam por vários lugares e se enredam com outros corpos pelas redes virtuais. Transitam, ou pelo menos pensam que transitam, sem barreiras, mas a certeza é que o fazem na velocidade da circulação do capital mundial. Esse, sim, sem fronteiras. Então não é preciso força bruta para impor as condições necessárias ao sistema, mas a mudança da força dos desejos. Corrompe-se a política do desejo.

Entretanto os autores referenciados discutem possíveis nesse contexto. Tamanho o estrago produzido nos processos de subjetivação, faz-se necessária uma descolonização dos inconscientes. E a descolonização dos inconscientes passa pelo terreno das relações mais íntimas e, ao mesmo tempo, das relações coletivas, comuns, da multidão (HARDT; NEGRI, 2005, 2016b; ROLNIK, 2018). A efetuação de possíveis é um processo necessário. A resistência é um dos possíveis. “[...] Esta resistência deve-se abrir a um processo de criação, de transformação da situação, de participação ativa nesse processo. Nisso consiste resistir [...]" (LAZZARATO, 2006, p. 21).

\section{Podem os corpos resistir?}

Como afirmamos, Suely Rolnik, Maurizio Lazzarato, Antonio Negri e Michael Hardt são autores que têm buscado problematizar os processos de subjetivação na contemporaneidade. $\mathrm{O}$ que estamos chamando de subjetivação?

\footnotetext{
${ }^{4}$ Daniel Cohen, Christian Mazzari, Carlo Vencellone, entre outros.
} 
Rolnik ([201-]) discute duas experiências simultâneas que fazemos/estabelecemos com o mundo. A primeira, que é imediata e se baseia na percepção, possibilita-nos uma apreensão desse mundo, que é inseparável do campo cultural, pois essa experiência é eivada de códigos, símbolos, representações que nos permitem atribuir sentidos ao que fazemos, tocamos, escutamos - o que a autora chama de "experiência do sujeito". Entretanto há uma experiência mais complexa - a subjetividade, que produz algo que está "fora-do-sujeito". "São as forças que agitam o mundo enquanto corpo vivo e que produzem efeitos em nosso corpo em sua condição de vivente. Tais efeitos consistem em outra maneira de ver e de sentir aquilo que acontece em cada momento" (ROLNIK, [201-], p. 10). O mundo vive em nosso corpo. Pulsa. São os perceptos ${ }^{5}$ e os afectos ${ }^{6}$ que não têm uma imagem ou palavras que os representam, mas são reais e "[...] dizem respeito à dimensão viva do mundo, cujos efeitos compõem um modo de apreensão extracognitivo" (ROLNIK, [201-], p. 10). É o que constitui o "saber-do-corpo". Isso não é uma experiência individual.

O mundo "vive" efetivamente em nosso corpo sob o modo de afectos e perceptos e integra sua/nossa composição, impulsionando o processo incessante de recriação de nós mesmos e de nosso entorno. Tais maneiras de ver e sentir formam uma espécie de germe de mundo que nos habita. Somos então tomados por um estranhamento porque o mundo de que este germe é portador é, por princípio, irrepresentável; ele é exatamente o que não cabe na cartografia cultural vivente e a coloca em risco de dissolução. É que por não corresponder à experiência da vida em seus novos arranjos de forças resultante de novas conexões entre os corpos, tal cartografia passa a asfixiá-la. (ROLNIK, [201-], p. 11).

Rolnik ([201-]) ainda nos mostra que essas duas experiências acontecem ao mesmo tempo e são indissociáveis. Mas a relação entre elas é paradoxal, gera tensão e acaba por desestabilizar a subjetividade, causando a sensação de mal-estar. Frente ao que vivemos, desenvolve-se uma política do desejo - que é o modo de resposta do desejo diante da experiência de desestabilização e mal-estar - que muda em função de uma época, uma forma de cultura. E o mais importante é que a subjetividade consegue se sustentar no mal-estar provocado pela tensão entre ambas, o que lhe dá condições para se manter à escuta dos afectos e perceptos responsáveis por sua desestabilização (ROLNIK, [201-], p. 14).

Essa política do desejo que se constitui no âmbito da micropolítica pode ser ativa ou reativa. No primeiro caso, "o mundo larvário que nela habita terá grandes chances de germinar: é na ação do desejo que se plasmará a germinação" (ROLNIK, [201-], p. 14). Esse germinar traz a força da criação, da pulsação, da contaminação, da reverberação das ressonâncias nas subjetividades, com o poder de contaminar todo o seu entorno. É

[...] um devir da subjetividade e de seu campo relacional imediato e, a partir dele, de outros campos relacionais que habitam as subjetividades que o compõem [...] capilarizando-se rizomaticamente pelo corpo do mundo e transformando sua paisagem [...] é a potência do vivo que as ações do desejo buscarão expandir para ampliar nossa condição de existir. O que a micropolítica ativa visa é, pois, à conservação da potência do vivo que se realiza num incessante processo de construção da realidade (ROLNIK, [201-], p. 16).

\footnotetext{
5 "É distinto de percepção, pois consiste numa atmosfera que excede as situações vividas e suas representações" (ROLNIK, 2018, p. 53).

6 "[...] emoção vital, a qual pode ser contemplada [...] no sentido do verbo afetar - tocar, perturbar, abalar, atingir

[...]. Perceptos e afectos [...] dizem respeito ao vivo em nós mesmos e fora de nós" (idem).
} 
A micropolítica reativa, segundo Rolnik ([201-]), decorre do inconsciente colonial capitalístico, que desativa a potência que o corpo tem para decifrar o mundo; e a subjetividade passa a ser orientada apenas por sua experiência de sujeito - a subjetividade antropo-falo-egologocêntrica - ou seja, começa e termina no próprio sujeito. E "por estar bloqueada em sua experiência fora-do-sujeito, ela se torna surda aos efeitos das forças que agitam o mundo [...] ignorando aquilo que o saber do corpo lhe indica" (ROLNIK, 2018, p. 65).

Dessa forma, "a cafetinagem da pulsão vital nos impede de reconhecê-la como nossa, o que faz com que a sua reapropriação não seja tão óbvia [...]” (NEGRI, 2015, p. 35). Aí reside o perigo da micropolítica reativa concernente a esse regime: ao separar a subjetividade de sua força vital, pulsional de germinação, interrompe a potência desejante de criação de outros mundos, ou seja, essa potência acaba por ser cafetinada. E esse processo acaba por contaminar toda a teia relacional, intoxica e estanca os processos de diferenciação e singularização. Somos todos tomados pelos efeitos da vida sujeitada a esse poder perverso, que gera "uma vida genérica, vida mínima, vida estéril, mísera vida" (ROLNIK, 2018, p. 76).

Schuchter e Amorim (2018) apontam que, das muitas transformações próprias às políticas neoliberais, chamam a atenção as mudanças no campo cultural, pelas formas de ser que geram novos processos de subjetivação. Essa preconizada nova ordem mundial, instaurada a partir dos anos de 1970 e aqui, no Brasil, no início dos anos de 1990, nada mais é que um processo de recolonização impetrado pelo imperialismo em relação aos países em desenvolvimento e subdesenvolvidos, mas principalmente dos corpos, das vidas, das subjetividades. Como afirma Rolnik, trata-se de impor um modo de vida de acordo com os desígnios neoliberais. É a supervalorização da mercadoria e do capital. Ideias já defendidas por Frederick Haeck, no livro Caminhos da servidão, em 1945, mas que não tiveram eco suficiente, pelo fato de ainda vivenciarmos os efeitos da primeira grande crise do sistema capitalista, em 1929, e pelo período de pós-Segunda Guerra Mundial, em que era necessária a ação do Estado de Bem-Estar Social e, nesse momento, era importante a integração do maior contingente de pessoas possível na esfera econômica e social para permitir a volta do fluxo/ciclo normal do capitalismo.

Diante de outra crise do sistema capitalista, em 1970, gerada também por um processo de superprodução, as soluções buscadas não serão mais a integração. Ao invés de um Estado de Bem-Estar Social, um Estado mínimo, com ações reduzidas no que tange ao campo social, constituindo-se como um ente regulador do campo econômico, com intervenções tópicas e assistemáticas, apenas para garantir o ciclo e o fluxo do capital e, assim, ao invés da integração, a exclusão social gerada pela diminuição e anulação de muitos direitos conquistados e garantidos. Essa exclusão vem só se agravando diante da diminuição dos postos de trabalho, dos processos de privatização, terceirização, flexibilização das leis trabalhistas e da negação de todos os direitos democráticos consolidados até então (SCHUCHTER; AMORIM, 2018).

Eis a questão central que Rolnik (2018) vem desenvolvendo. Não é apenas a exclusão física, do corpo, ou econômica. Não se trata mais do disciplinamento dos corpos, mas sim da gestão das diferenças (LAZZARATO, 2011). As técnicas disciplinares e as técnicas biopolíticas desenvolvidas no período de implementação do Estado Nação foram políticas que supunham “"...] a neutralização e o controle, em escala social, da lógica do acontecimento, da criação e da produção do novo" (LAZZARATO, 2006, p. 71). O poder era localizado e visava a um padrão de comportamento que se repetia, por meio de dispositivos que buscavam aprisionar a multiplicidade, a potência de transformação, o devir, "[...] neutralizando a diferença e a repetição e sua potência de variação [...] subordinando-a à reprodução" (LAZZARATO, 2006, p. 69).

$\mathrm{Na}$ versão do capitalismo financeirizado e neoliberal, 
[...] o problema não é mais o de aprisionar o fora e disciplinar as subjetividades quaisquer [...]. Não se trata, portanto, de discipliná-las em um espaço fechado, mas de modulá-las em um espaço aberto. O controle se superpõe, dessa maneira à disciplina [...]. O tempo do acontecimento, da invenção e da criação de possíveis não pode mais ser considerado uma exceção, mas aquilo que faz regular e capturar cotidianamente (LAZZARATO, 2006, p. 72).

A forma de poder nessa sociedade - de controle - é diferente e se sustenta nos aparatos da informação, da tecnologia, das redes de comunicação, dos mecanismos virtuais, dos fluxos e redes, dos dispositivos tecnológicos que agem a distância e que produzem os processos de subjetivação e sujeição correspondentes com capacidade de afetar e ser afetado dos cérebros, midiatizada pela tecnologia. Isso é "[...] estratégico para o controle do processo de constituição do mundo social" (LAZZARATO, 2006, p. 76). São formas de controle gestadas em um neocapitalismo que "[...] atinge as raízes da existência. Ele faz mais que exigir submissão e obediência; ele molda e modula a subjetividade e a vida dos indivíduos" (LAZZARATO, 2014, p. 116).

Esse controle da vida, da subjetividade é um dos aspectos fundamentais do regime capitalista financeirizado, neoliberal - condição para o processo de colonização referido anteriormente - e, para levar isso a cabo, supera todas as artimanhas e estratégias utilizadas até então. A intervenção passa por um refinamento e intensificação. O intuito agora não é apenas deixar o corpo dócil e submisso, mas acelerar ao mesmo tempo sua capacidade de produção do que interessa ao regime e o alto consumo desses mesmos produtos, desviando-o de seu destino ético, que é a capacidade de criação associada à vida. Nessa armadilha, nossos corpos passam a reproduzir também o status quo. Assim, "[...] apenas muda-se, criativamente, suas peças de lugar, fazendo variações sobre o mesmo" (ROLNIK, 2018, p. 164). Então, se antes eram os corpos dóceis, agora são necessários os corpos flexíveis, voláteis, criativos, conectados, maleáveis, que circulam por vários lugares, enredam-se com outros corpos pelas redes virtuais. Transitam, ou pelo menos pensam que transitam, velozmente, sem barreiras. A única certeza é que o fazem com a mesma velocidade de circulação do capital mundial. Esse, sim, sem barreiras, sem fronteiras. Então não é necessária a força bruta ou o panóptico para impor suas condições e o controle, mas a mudança da força dos desejos. "A potência do desejo é desviada de seu destino ativo criador para se transformar em potência reativa de submissão: esse é o real perigo" (ROLNIK, [201-], p. 23). São forças altamente destrutivas que vêm gerando um malestar generalizado, uma sensação de perplexidade, um pavor e a produção de muita angústia.

Segundo Rolnik (2018), o que vemos hoje é algo que, num primeiro momento, parece paradoxal, contraditório, que é a aliança entre neoliberalismo e neoconservadorismo extremo, porque o alto grau de complexidade e flexibilidade do atual regime de acumulação está longe do arcaísmo e rigidez das forças conservadoras. Entretanto é possível compreender os motivos que levam a essa aliança: nesse momento se fazem necessárias forças bem rudes e abrutalhadas para destruir, por fim, todas as conquistas democráticas conquistadas e fazer ruir todos os protagonistas dessas conquistas e todas as suas influências sobre a sociedade. E, de preferência, demonizando esses protagonistas.

Isso nos faz compreender - citando aqui apenas dois exemplos - o caso de Luiz Inácio Lula da Silva, que terminou seu governo como um dos presidentes mais bem avaliados da história do Brasil, que hoje é proclamado por parte da população que aprovava seu governo como um bandido de alta periculosidade e, junto com todo o Partido dos Trabalhadores, fonte de toda corrupção no Brasil. Isso nos faz compreender por que Dilma sofreu o impeachment por um crime não cometido, ou pelos menos que outros já haviam cometido e que não foram afastados de seus postos de comando. E isso tudo em meio aos nossos gritos: Não vai ter golpe! Como agravamento da situação, temos que considerar que essa não é apenas uma experiência 
brasileira, mas de todos os governos em escala mundial, principalmente América Latina, de tendência democrática e popular. E nossa sensação é de impotência, angústia, mal-estar, adoecimento, perplexidade, assombramento.

Mas, quando somos tomados por esses sentimentos, aloja em nós a política de subjetivação guiada pelo inconsciente colonial cafetinístico. Perdemos a potência do combate da micropolítica ativa e tendemos a nos deixar levar pela micropolítica reativa ou a reduzir nossas análises à esfera macropolítica, com foco nas questões sobre a crise da democracia e do Estado de direito, ou sobre como recuperar as condições de vida democrática e resgatar esse Estado. Nesse ínterim, nossa incapacidade aflora e dá condições para que as forças regressivas e conservadoras do mal germinem.

Lazzarato $(2014$, p. 23) aponta que a crise que vivenciamos “[...] produz apenas sujeições negativas e regressivas (o homem endividado)". Endividado por quê? Nesse contexto, no reino do capital e da mercadoria, o consumo passa a ser visto como uma das poucas possibilidades para a felicidade, mas o consumo endivida. Assim, o consumo também acaba por alimentar paixões tristes, e a responsabilização pelas dívidas e tristezas recai sobre cada um de nós individualmente. Em outra obra, o mesmo autor (2017, p. 27) pergunta: "O que acontece com o homem endividado na crise? Qual sua principal atividade? [...] ele paga. Ele deve expiar sua falta - a dívida - pagando sem cessar [...]".

Como alternativa, o regime conclama as pessoas a se tornarem "empresárias de si mesmas", o que é "[...] o objetivo do capital como máquina de assujeitamento" (LAZZARATO, 2014, p. 23). Assim, como afirmamos, "[...] com o neoliberalismo, as práticas de governo passam pelo indivíduo, pela sua subjetividade, por seus comportamentos e por seus estilos de vida" (LAZZARATO, 2014, p. 45).

Hardt e Negri (2016b) apontam que o apogeu do neoliberalismo gerou crises na vida econômica e política, mas, principalmente, operou transformações sociais e antropológicas. E, junto com os outros autores aqui referenciados, problematizam as consequentes formas de fabricação/produção de novas figuras de subjetividade. Para eles, além da subjetividade endividada criada pela hegemonia das finanças e dos bancos, o

[...] controle das informações e das redes de comunicação criaram o mediatizado. $\mathrm{O}$ regime de segurança e o estado generalizado de exceção construíram a figura oprimida pelo medo e sequiosa de proteção: o securitizado. E a corrupção da democracia forjou uma figura estranha, despolitizada: o representado (HARDT; NEGRI, 2016b, p. 21).

O mediatizado é aquele cercado por todas as mídias digitais, que é forçado a todo tempo a se exprimir, não tendo vacúolos de solidão e silêncio, para, enfim, ter algo a dizer. Exercitar o direito de não ter nada a dizer. Fazer a experiência do silêncio, para que exista o pensamento, para que se tenha algo de valor a dizer. O mediatizado fica, assim, cercado de informações mortas que sufocam o poder de criar, de pensar (HARDT; NEGRI, 2016b).

O securitizado é cercado por informações que são produzidas sobre sua vida: é o escâner no aeroporto, é a coleta de suas digitais, de sua retina, são os dados bancários, os livros que consome e a lista dos que se relacionam com os que comprou, os filmes a que assiste e a lista que é criada a partir desses filmes e que lhe é sugerido que assista, o mapeamento dos lugares que você esteve, as câmeras de segurança, o controle de suas compras no cartão de crédito, entre outros. "Nos últimos anos, as tecnologias de segurança avançaram muito, investigando atentamente a sociedade, as nossas vidas e os nossos corpos [...] A prisão começa bem antes de suas portas. Desde que você sai de sua casa [...] e até mesmo antes" (HARDT; NEGRI, 2016b, p. 33). Vivemos em um estado de exceção, sem que nos demos conta disso. 
O representado é fruto da "democracia representativa", seria um instrumento de inclusão política das populações, mas "representar significa tornar presente uma ausência, ou em realidade, um ninguém" (HARDT; NEGRI, 2016b, p. 44). Os autores ainda afirmam que junto às outras subjetividades, o representado condensa o resultado de sua subordinação e corrupção.

Reiteramos que essas "novas" subjetividades tendem a consolidar a morte da potência do vivo, do poder de criação, pulsação e singularização. Tornamo-nos reféns. Rolnik ([201-]) discute o quanto isso ainda é fortalecido pela ideia de deficiência de si mesmo, e o mal-estar transforma-se ainda em sentimento de culpa, inferioridade, autodepreciação, vergonha ou ódio, ressentimento. Então, além do consumo, o desejo conectará a subjetividade a produtos de tarja preta da indústria farmacológica, a igrejas ou terapias de treinamento da autoestima ou aos complexos discursos intelectuais. Segundo o autor, "[...] tais mercadorias são usadas como perfumes para esconder o odor infecto de uma vida estagnada" (ROLNIK, [201-], p. 20).

Os autores referenciados discutem possíveis nesse contexto. Tamanho o estrago produzido nos processos de subjetivação, é necessária uma descolonização dos inconscientes. E a descolonização dos inconscientes passa pelo terreno das relações mais íntimas e, ao mesmo tempo, das relações coletivas, comuns da multidão (HARDT, NEGRI, 2005, 2016a; ROLNIK, 2018). A efetuação de possíveis é um processo necessário. A resistência é um dos possíveis. “[...] Esta resistência deve-se abrir a um processo de criação, de transformação da situação, de participação ativa nesse processo. Nisso consiste resistir [...]” (LAZZARATO, 2006, p. 21).

Lazzarato (2014, p. 195) vai nos dizer que

[...] o capitalismo atual, com suas empresas e instituições, prescreve um cuidado de si e um trabalhar sobre si, ao mesmo tempo físicos e psíquicos, um "bem viver" e uma estética da existência que parecem desenhar as novas fronteiras da sujeição capitalista e da valorização econômica, que assinalam um empobrecimento sem precedentes da subjetividade.

O mesmo autor retoma Foucault, que discute os processos de subjetivação interrelacionados às práticas discursivas e aos mecanismos destinados a conduzir a conduta dos homens, ou seja, a tríade sujeito-poder-saber. E é também Foucault que "[...] descreve a subjetivação como um processo imanente de ruptura e constituição do sujeito" (LAZZARATO, 2014, p. 199). Aí residem os possíveis. Por quê? Compreendemos que esse regime, essa "nova" ordem é uma construção histórica, ideológica, discursiva. Se é uma construção histórica, é uma construção humana. Se é uma construção humana, podemos intervir. Se podemos intervir, podemos crer que outros corpos, outras formas de viver, outros mundos, outras sociedades são possíveis. Um mundo sem tristeza. Nossa aposta são mundos sem tristeza - a aposta deles é o contrário. Apostam na tristeza. Porque nada alimenta mais este sistema que a nossa tristeza, porque a tristeza nos fragiliza e imobiliza. Assim, nada alimenta mais o capitalismo que a nossa tristeza. A tristeza nos impede de lutar pelo que acreditamos.

\section{Considerações finais}

Os autores referenciados neste artigo têm apontado algumas formas de insurgir, resistir e produzir novos/outros processos de subjetivação que tendem a superar ou minimizar os efeitos perversos e destrutivos do inconsciente colonial cafetinístico. Não basta resistir macropoliticamente, "é preciso o combate pela potência afirmativa de uma micropolítica ativa - enfrentar a situação no plano da subjetividade, do desejo e do pensamento - onde o capitalismo se sustenta". (ROLNIK, 2018, p. 35-36). Precisamos liberar a vida da cafetinagem - extração da potência de vida, do poder vital de pulsação - para poder encontrar os pontos em 
que o desejo poderá perfurar as condições impostas por esse inconsciente, para neles inscrever os cortes da força instituinte (ROLNIK, 2018).

A autora nos indica, ainda, a necessidade de pensar e resistir. A ideia do pensar supõe escutar, sentir os efeitos das forças da atmosfera ambiente no nosso corpo, mas ao mesmo tempo sentir a pulsação de mundos larvares que são também gerados e fecundados em nosso corpo e anunciam o saber-do-vivo e implicar-se com esse saber, em um movimento de desterritorialização que tais gérmens de mundo disparam. Para Rolnik, isso tem a capacidade de um contágio potencializador das subjetividades e pode nos levar a substituir a perspectiva antro-falo-ego-logocêntrica por uma perspectiva ético-estético-clínico-política.

Junto com Hardt e Negri, Rolnik apela para a construção/formação/constituição do comum, "para isso é preciso tomar para si a responsabilidade como ser vivo e lutar pela reapropriação das potências de criação e cooperação e pela construção do comum que dela depende" (ROLNIK, 2018, p. 89). Para Hardt e Negri (2016a, p. 283), a produção do comum exige a "[...] abertura à alteridade e à capacidade de formar relações com os outros, de gerar encontros prazerosos e assim criar corpos sociais com capacidade sempre maiores", recuando das relações destrutivas e dos corpos perniciosos que essas relações produzem. Os autores apostam, assim, em um acontecimento biopolítico e retomam Deleuze, que já nos dizia que esse acontecimento é uma prática daqueles que acreditam no mundo, é o poder de não só escapar ao controle do inconsciente colonial capitalístico, como também criar um novo mundo. O acontecimento biopolítico é, assim, uma subversão ao processo de subjetivação que abala identidades e normas dominantes, remete-nos à ideia de poder e liberdade e inaugura uma produção alternativa de subjetividades.

Lazzarato (2006), nessa mesma direção, fala-nos que as singularidades individuais e coletivas, ao constituírem esses processos de subjetivação, afirmam as diferenças e a composição de um mundo não totalizável, ou seja, não desejam a ideia de um só mundo. A política agora não deve se apoiar apenas na ideia do estou contra, mas no estamos juntos. Entretanto é um estar juntos que supõe a perspectiva da multiplicidade e diferenciação, o que possibilita a proliferação de outros mundos possíveis.

Como pensar em outras formas de viver? Como libertar nossos corpos? O que pode nossos corpos? Acreditamos que precisamos pensar e viver a política como modo de criação de vida, não como algo transcendente, abstrato, mas imanente. Política como produção do comum. O que estamos vivendo precisa nos tensionar a criar outros mundos, outras formas de viver, outras escolas, outras formas de política.

Desde o início deste trabalho, discutimos os processos de subjetivação na contemporaneidade, que parece assinalar para uma dessubjetivação (PELBART, 2019), que é um processo de abandono de si, do mundo, da vida, da luta. E o que acomete nossos corpos, perpassa, invade a sociedade e nossas vidas, produzindo a patologização dos processos vividos, a melancolia e a desesperança, a desterritorialização que faz com que todos se sintam desambientados, sem lugar. Entretanto essa desterritorialização pode ser positiva, no sentido de nos encaminhar para outras direções, de nos sacudir. Pode nos levar a insurgir, resistir, burlar o sistema e todas suas formas de opressão e vigilância. Criar táticas de não só sobreviver, mas de produzir novas formas de viver. Se não for possível tocar violino, pelo menos parar para ouvir e sentir o som do violino.

Apostamos, assim, que, apesar de vivermos um momento de mais alta periculosidade, que afeta não apenas questões da ordem econômica, mas dimensões da ordem cultural e social ligadas diretamente aos nossos corpos, às nossas vidas, individuais e coletivas, aos processos de subjetivação, não podemos sucumbir. Isso é o que o regime financeirizado neoliberal espera de nós.

É decisivo, pois, que habitemos todos os lugares e especificamente os espaços onde vivemos e atuamos, com nossa alegria e vontade de criação. Que transformemos esses espaços em lugares de bons e potentes encontros, de transbordamento de afetos alegres. Nesse sentido, 
é fundamental que utilizemos em nosso trabalho, em nossa vida, mecanismos disparadores de outras subjetividades, que possamos problematizar as subjetividades que estão sendo produzidas pelo regime atual e que sejam subjetividades que, no mínimo, questionem e duvidem das práticas discursivas que querem nos fazer acreditar que tudo decorre de uma ordem natural e inevitável. Temos que reafirmar que o inevitável é a vida. Vida digna. Vida plena. Vida alegre. Vida pulsante. Corpo livre! Corpo sadio! Corpo vibrante!

\section{Referências}

HARDT, M.; NEGRI, A. Multidão. Rio de Janeiro: Record, 2005.

HARDT, M.; NEGRI, A. Declaração - Isto não é um manifesto. 2. ed. São Paulo: n-1 edições, 2016a.

HARDT, M.; NEGRI, A. Bem estar comum. Rio de Janeiro: Record, $2016 \mathrm{~b}$.

LAZZARATO, M. As revoluções do capitalismo. Rio de Janeiro: Civilização Brasileira, 2006.

LAZZARATO, M. O governo das desigualdades: crítica da insegurança neoliberal. São Carlos: EdUFSCAR, 2011.

LAZZARATO, M. Signos, máquinas, subjetividades. São Paulo: Edições Sesc, 2014.

LAZZARATO, M. O governo do homem endividado. São Paulo: n-1 edições, 2017.

NEGRI, A. Biocapitalismo e constituição política do presente. In: NEGRI, A. (Org.). Biocapitalismo: entre Spinoza e a constituição política do presente. São Paulo: Iluminuras, 2015. p. 57-84.

PELBART, P. P. Ensaios do assombro. São Paulo: n-1 edições, 2019.

ROLNIK, S. Esferas da insurreição: notas para uma vida não cafetinada. São Paulo: n-1 edições, 2018.

ROLNIK, S. A hora da micropolítica. São Paulo: n-1 edições, [201-].

SCHUCHTER, T. M.; AMORIM, F. L. A. Políticas de inclusão e políticas de currículo no contexto contemporâneo: das sociedades disciplinares às sociedades de controle. Revista Espaço do Currículo, João Pessoa, v. 11, n. 2, p. 260-275, maio/ago. 2018.

VEIGA-NETO, A. Cultura, culturas e educação. Revista Brasileira de Educação, n. 23, p. 515, maio/jun./jul./ago. 2003. 